\title{
molecules
}

ISSN 1420-3049

(C) 2007 by MDPI

www.mdpi.org/molecules

Review

\section{Litchi Flavonoids: Isolation, Identification and Biological Activity}

\author{
Jiangrong $\mathrm{Li}^{1}$ and Yueming Jiang ${ }^{1,2, *}$
}

${ }^{1}$ College of Food Science, Biotechnology and Environmental Engineering, Zhejiang Gongshang University, Hangzhou, 310035, The People’s Republic of China; e-mail: lijianrong@zjgsu.edu.cn

2 South China Botanical Garden, Chinese Academy of Sciences, Guangzhou 510650, The People’s Republic of China

* Author to whom correspondence should be addressed; E-mail: ymjiang@scib.ac.cn.

Received: 14 March 2007; in revised form: 26 March 2007 / Accepted: 28 March 2007 /

Published: 11 April 2007

\begin{abstract}
The current status of the isolation, identification, biological activity, utilization and development prospects of flavonoids found in litchi fruit pericarp (LFP) tissues is reviewed. LFP tissues account for approximately 15\% by weight of the whole fresh fruit and are comprised of significant amount of flavonoids. The major flavonoids in ripe LFP include flavonols and anthocyanins. The major flavanols in the LFP are reported to be procyanidin B4, procyanidin B2 and epicatechin, while cyanindin-3-rutinside, cyanidin-3glucoside, quercetin-3-rutinosde and quercetin-3-glucoside are identified as the important anthocyanins. Litchi flavanols and anthocyanins exhibit good potential antioxidant activity. The hydroxyl radical and superoxide anion scavenging activities of procyanidin B2 are greater than those of procyanidin B4 and epicatechin, while epicatechin has the highest $\alpha, \alpha$-diphenyl- $\beta$-picrylhydrazyl radical (DPPH·) scavenging activity. In addition to the antioxidant activity, LFP extract displays a dose- and time-dependent inhibitory effect on human breast cancer, which could be attributed, in part, to its inhibition of proliferation and induction of apoptosis in cancer cells through up-regulation and down-regulation of multiple genes. Furthermore, various anticancer activities are observed for epicatechin, procyanidin B2, procyanidin B4 and the ethyl acetate fraction of LFP tissue extracts. Procyanidin B4 and the ethyl acetate fraction show a stronger inhibitory effect on HELF than MCF-7 proliferation, while epicatechin and procyanidin B2 have lower cytotoxicities towards MCF-7 and HELF than paclitaxel. It is therefore suggested that flavonoids from
\end{abstract}


LFP might be potentially useful components for functional foods and/or anti-breast cancer drugs.

Keywords: Litchi; fruit; pigments; isolation; identification; antioxidant; anticancer; activity; flavonoids; utilization.

\section{Introduction}

Litchi (Litchi chinensis Sonn.) is a tropical to subtropical crop that originated in South-East Asia. As litchi fruits became gradually accepted by consumers for their delicious taste and attractive red skin, litchi production has steadily increased over recent decades, with increasing exports into Europe and North America from both southern and northern hemisphere production areas [1, 2]. Litchi fruit pericarp (LFP) accounts for approximately $15 \%$ by weight of the whole fresh fruit and is comprised of significant amount of flavonoids [2], therefore litchi LFP tissues may be considered an important source of dietary flavonoids.

Naturally occurring flavonoids are generally classified into six classes according to their chemical structures (Figure 1), i.e. flavanones, flavones, isoflavonoids, flavans (flavanols), flavonols and anthocyanins by the structure of the C-ring and the functional groups at C-3 and C-4 [3]. In general, all flavonoids can be considered derivatives of the 2-phenylchromone parent compound composed of three phenolic rings, referred to as the A-, B- and C-rings, all of which contain varying levels of hydroxylation and methoxylation $[4,5]$. Anthocyanins belong to a wider class of phenolic compounds and are glycosides of polyhydroxy and polymethoxy derivatives of 2-phenylbenzopyrylium or flavylium salts (Figure 2) [3, 6]. The most common sugar components of anthocyanins are glucose, galactose and arabinose, which are usually conjugated to the anthocyanidin molecule via the C-ring C-3 hydroxyl group [8]. The differences between individual anthocyanins relate to the number of hydroxyl groups, the nature and number of sugars attached to the molecule, the position of this attachment and the nature and number of aliphatic or aromatic acids attached to the sugars in the molecule [7,8]. Some anthocyanins comprise multiple sugar moieties involving hydroxyl functionalities of the aglycon molecule other than the C-3 one [9].

Many studies have shown that flavonoids play important pharmacological roles against various human diseases, such as cardiovascular disease, cancer, inflammation and allergies [4, 10-14]. Like several other flavonoids, litchi anthocyanins are powerful free radical scavengers and exhibit strong antioxidant activity in lipid environments such as emulsified methyl linoleate, human low-density lipoprotein and liposomes [15-16]. Thus, LFP tissues can be used as a readily accessible source of natural antioxidants and/or a possible supplement in the food or pharmaceutical industries. To better utilize LFP tissues, this paper overviews advances in the isolation, identification and biological activities of flavonoids in relation to their utilization. 
Figure 1. Molecular structures of flavonoids adapted from Peterson and Dwyer (arrows indicate biosynthetic path) [3]. The basic structure consists of the fused A- and C-ring, with the phenyl B-ring attached to through its 1-position to the 2-position of the C-ring.

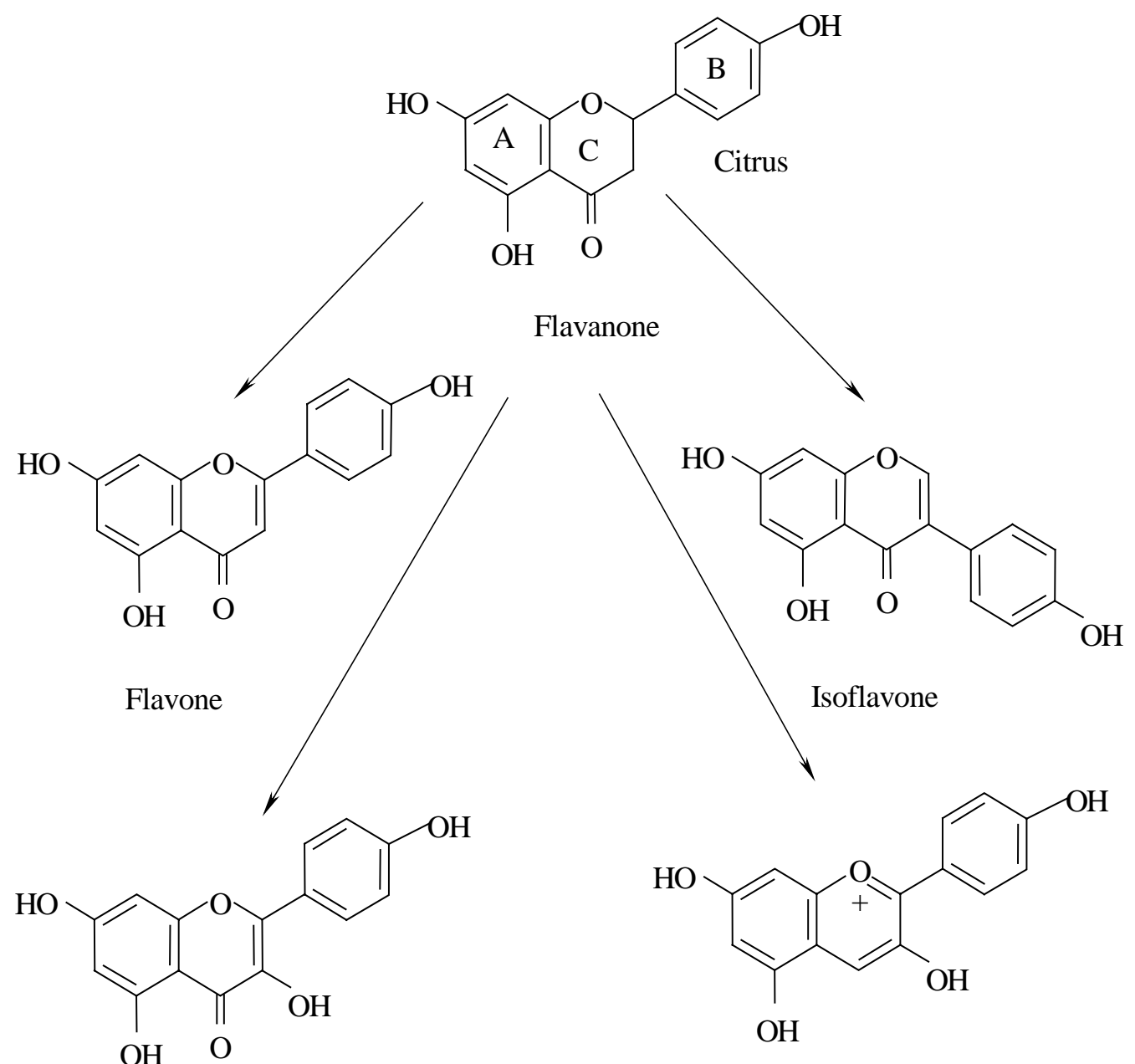

Flavonol

$$
\text { Anthocyanin }
$$<smiles>Oc1cc(O)c2c(c1)O[C@H](c1ccc(O)c(O)c1)[C@H](O)C2</smiles>

Catechin<smiles>Oc1cc(O)c2c(c1)O[C@H](c1ccc(O)c(O)c1)[C@H](O)C2c1c(O)cc(O)c2c1O[C@H](c1ccc(O)c(O)c1)[C@H](O)C2</smiles>

Flavans 
Figure 2. The flavylium cation. $\mathrm{R} 1$ and $\mathrm{R} 2$ are $\mathrm{H}, \mathrm{OH}$, or $\mathrm{OCH}_{3}$ while $\mathrm{R} 3$ is a glycosyl or $\mathrm{H}$ and $\mathrm{R} 4$ is $\mathrm{OH}$ or a glycosyl $[3,6]$.

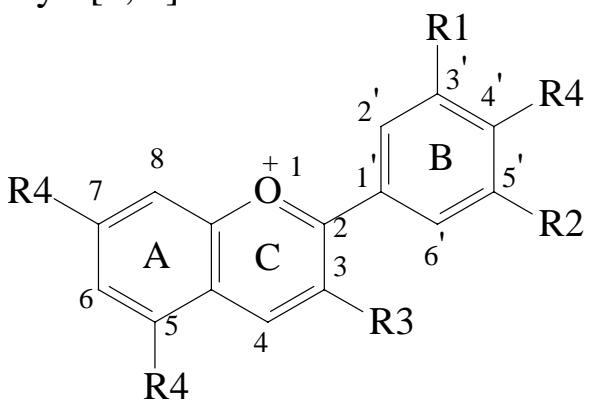

\section{Extraction and purification of flavonoids}

LFP contains large amounts of pigments which are mainly comprised of flavonoids. Most pigments present in ripe LFP tissues are soluble in polar solvents, and they can be extracted using methanol containing small amounts of hydrochloric or formic acid $[16,17]$, as the low $\mathrm{pH}$ value of the extraction solutions prevents the degradation of these pigments. However, as hydrochloric or formic acid are concentrated during the evaporation of the methanol-hydrochloric acid or methanol-formic acid solutions, pigment degradation occurs. Small amounts of dilute acid may also cause partial or total hydrolysis of the acyl moieties of acylated pigments that are present in some plant tissues [6]. Zhao et al. [16] reported that flavonoids were extracted from LFP tissues with 85:15 ethanol-HCl, that most of the flavonoids were partitioned into the ethyl acetate fraction, and three major components could be obtained using a reverse phase high-performance liquid chromatography (HPLC) method.

As LFP tissues contain a large amount of anthocyanins, considerable attention has been paid in recent years to their isolation and purification. These anthocyanins are strongly bound to chromatographic adsorbents through their unsubstituted hydroxyl groups and can be separated from unrelated compounds using a series of solvents of increasing polarity [6, 7, 18]. A comparative analysis demonstrated that litchi anthocyanins can be extracted effectively with $0.5 \mathrm{M}$ hydrochloric acid [19]. Amberlite XAD-7 column or Sephadex LH-20 column chromatography are commonly used for the initial purification of the crude anthocyanin extracts. Zhang et al. [20] reported that litchi anthocyanins can be easily purified using an Amberlite XAD-7 column, followed by a Sephadex LH20 column, and a major anthocyanin from LFP tissues, accounting for $94.3 \%$ of total, was obtained after the purification sequence. Nevertheless, techniques for rapid purification of anthocyanins from LFP tissues need to be improved to meet the requirements of the high mass sensitivity and resolution with the low sample consumption and minimal generation of solvent wastes.

\section{Identification of flavonoids}

The identification of plant flavonoids usually involves the separation of each compound, and subsequent analysis by mass (MS) and nuclear magnetic resonance (NMR) spectroscopy [13]. For the separation and structural analysis, the use of the liquid chromatography-mass spectrometry (LC-MS) technique, which combines the separation power of LC with the high selectivity and sensitivity of the MS detector, permits the identification and quantification of individual compound in a flavonoid 
mixture. Prasad and Jha Prasad [21] first reported the red pigments in LFP tissues to be anthocyanins. Subsequently, Lee and Wicker [22, 23] noted six different types of anthocyanins present in LFP tissues: cyanidin-3-rutinoside, cyanidin-3-glucoside, cyanidin-3-galactoside, malvidin-3-acetylglucoside, pelargonidin-3-glycoside and quercetin 3-rutinoside. Using HPLC Zhang et al. [17] and Sarni-Manchado et al. [24] identified the important anthocyanins in LFP tissues as cyanindin-3rutinoside, cyanidin-3-glucoside, quercetin-3-rutinoside and quercetin-3-glucoside. Glässgen et al. [25] introduced the application of liquid chromatography - electrospray ionization mass spectrometry (LCESI-MS) for the identification of individual anthocyanins in plant tissues. Zhang et al. [20] showed that the major anthocyanin of LFP tissues was cyanindin 3-rutinoside using this technique. Zhao et al. [16] reported that three major flavonoid components obtained by reverse phase HPLC of the ethyl acetate fraction of LFP tissues were determined to be flavanols by their ultraviolet/visible spectra and further identified them as procyanidin B4, procyanidin B2 and epicatechin (Figure 3) by combined MS and NMR methods. Due to the number of litchi cultivars that are known, differences in compositions and contents of flavonoids in LFP tissues could exist. To better understand the type and proportions of pigments present in LFP tissues, the identification and quantification of each flavonoid and anthocyanin in various cultivars should be investigated.

Figure 3. Molecular formulae of epicatechin, procyanidin B2 and procyanidin B4.<smiles>Oc1cc(O)c2c(c1)O[C@H](c1ccc(O)c(O)c1)[C@H](O)C2</smiles>

Epicatechin<smiles>Oc1cc(O)c2c(c1)O[C@H](c1ccc(O)c(O)c1)C(O)C2c1c(O)cc(O)c2c1O[C@H](c1ccc(O)c(O)c1)[C@H](O)C2</smiles>

Procyanidin B4<smiles>Oc1cc(O)c2c(c1)O[C@H](c1ccc(O)c(O)c1)[C@H](O)C2c1c(O)cc(O)c2c1O[C@H](c1ccc(O)c(O)c1)[C@H](O)C2</smiles>

Procyanidin B2

\section{Analysis of flavonoids}

Quantification of plant flavonoid mixtures involves separation and collection of each component and subsequent analysis. The lack of suitable standards necessitates a long and tedious procedure for the identification of known compounds. LC-MS combines the separation power of LC with the selectivity and sensitivity of the MS detector, permitting the identification and quantification of 
individual components of a mixture of flavonoids. The application of LC-MS methods to food analysis and the measurement of plant phenols has been recently reviewed [26, 27]. These techniques are successful for the identification and quantification of flavonoids in plant tissues, but they take a long time and require expensive equipment. Thus, it is necessary to develop a simple and rapid method for determination of major flavonoids when analysing a large number of samples [28]. Based on the identification of known flavonoids, a useful HPLC method for determination of major flavonoids in LFP tissues has been established by improving the elution system [17]. However, the nature of some minor flavonoids present in LEP tissues remains unclear and these require further identification.

\section{Flavonoid contents}

LFP tissues contain large amount of pigments including mainly flavonoids (Table 1), but the red pigments are progressively degraded due to formation of polymeric brown pigments [29, 30].

Table 1. Phenolic compounds and pigments in pericarp tissues of 'Huaizhi’ fruit [17].

\begin{tabular}{|l|c|}
\hline \multicolumn{1}{|c|}{ Phenolic compounds } & Area (\%) \\
\hline Gallic acid & 0.4 \\
Procyanidin B1 & 1.0 \\
(+)-Catechin & 1.6 \\
(+)-Gallocatechin & 1.1 \\
Procyanidin B4 & 5.3 \\
Procyanidin B2 & 11.4 \\
(-)-Epicatechin & 32.5 \\
(-)-Epigallocatechin & 10.9 \\
(-)-Epicatechin-3-gallate & 0.3 \\
Cyanidin-3-glucoside & 31.7 \\
Malvidin-3-glucoside & 3.8 \\
\hline
\end{tabular}

Zhang et al. [17] reported that the concentrations of the major anthocyanin compounds in LFP tissues decreased during storage. In addition, Zhao et al. [16] determined that the flavonoid content present in FLP tissues was about $25 \mathrm{mg} / \mathrm{g}$ dry weight (Table 2). However, LFP tissues of various cultivars can contain significantly amounts of flavonoids. The 'Huaizhi' cultivar, for example, has the highest antyocyanin concentration (unpublished data from the author's laboratory).

Table 2. Comparison of flavonoid contents in hexane, ethyl acetate, butanol and water fractions of litchi fruit pericarp tissues [10].

\begin{tabular}{|l|c|c|}
\hline Solvent fraction & $\begin{array}{c}\text { Flavonoid content } \\
\text { (mg/g dried weight) }\end{array}$ & Percent flavonoids \\
\hline Hexane & 0.04 & 0.2 \\
Ethyl acetate & 21.3 & 83.1 \\
Butanol & 3.5 & 13.6 \\
Water & 0.8 & 3.1 \\
\hline
\end{tabular}




\section{Stability of flavonoids}

Most flavonoids present in plant tissues are relatively unstable. For LFP, available knowledge about flavonoids mainly involves anthocyanins. Due to the electronic deficiency of their flavylium nuclei anthocyanins may undergo reactions that alter their structures [31]. The stability of litchi anthocyanins increases with the number of methoxyls in the B-ring and decreases as the number of hydroxyls increases [6, 19]. Glycosylation and acylation of the sugars also increase stability and, therefore, the diglycosides are more stable than their corresponding monoglycosides [31, 32]. Among the most common anthocyaninidins, the most stable is malvidin, followed by peonidin, petunidin, cyanidin and delphinidin [6]. In general, anthocyanins are water-soluble, and occur in different $\mathrm{pH}$ dependent conformations with varying colours or colour intensities (Figure 4). At $\mathrm{pH}<3$, the middle ring (C-ring) of the predominant anthocyanin conformer harbours a flavylium cation which confers intense colour to the molecule, while the stability of the flavylium cation, as judged by UV-VIS spectrophotometry, is compromised by increasing the $\mathrm{pH}$ to 8 or 9 .

Figure 4. pH-Dependent conformational rearrangement of anthocyanin molecule (G1: a sugar). At neutral $\mathrm{pH}$ anthocyans occur as chalcones with an open $\mathrm{C}$ ring (i). Under mildly acidic conditions the ring is closed to form a carbinol pseudobase (ii). In strong acid ( $\mathrm{pH} 2$ ), ring $\mathrm{C}$ acquires aromaticity involving a flavylium cation, which imparts intense colour to the molecule (iii). In alkali, oxidation of ring A generates a quinoid structure with elimination of the positive charge, this species is also coloured (iv). The ring-opened chalcone can be reformed at neutral $\mathrm{pH}$ [13].<smiles>[R]c1cc(C(=O)/C(=C\c2c(O)cc(O)cc2O)OCl)cc([R])c1O</smiles>

(i) Chalcone (Yellow)<smiles>[R]c1cc(-c2oc3cc(=O)cc(O)c-3cc2Cl)cc([R])c1O</smiles>

(iv) Quinoidal base (Coloured)<smiles>[R]c1cc(C2(O)Oc3cc(O)cc(O)c3C=C2Cl)cc([R])c1O</smiles>

(ii) Carbinol pseudo-base (Colourless)

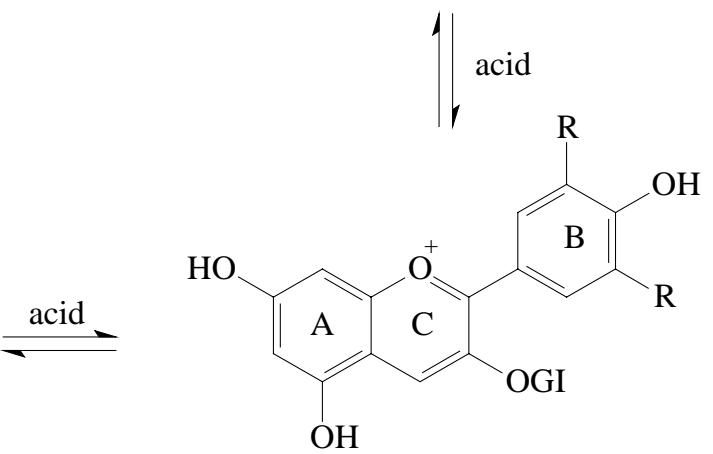

(iii) Flavylium cation (Coloured) 


\section{Functions of flavonoids}

Fruits and vegetables are a rich source of flavonoids [33]. Flavonoids are postulated to play pivotal roles in the adaptation to their biological environments both as defensive compounds (phytoalexins) and as chemical signals. As mentioned above, the most significant function of major pigments, such as anthocyanins, is their ability to impart colour to the plants or plant products in which they occur [6,34]. In addition, anthocyanins can play a definite role in the attraction of animals for pollination and seed dispersal, and hence they are of considerable value in the co-evolution of these plant-animal interactions [31]. Anthocyanins have also roles in flowering plants other than as attractants [14].

The anthocyanin-health properties are due to their peculiar chemical structures, as they are very reactive towards reactive oxygen species (ROS) because of their electron deficiency [5, 35, 36]. In the last years, great attention was given to the possible protection exerted by natural antioxidants present in dietary plants, particularly flavonoids and polyphenols, towards tissue injury mediated by ROS [3739]. The major pharmacological effects of LFP flavonoids include their antioxidant functions and anticancer activity.

\section{Pharmacological properties of flavonoids}

\section{8a. Antioxidant activity}

LFP extract contains significant amounts of polyphenolic compounds. There is some indirect evidence for the antioxidant potential of litchi pigments such as anthocyanins and flavanols $[15,16]$. Anthocyanins and flavanols can prevent the oxidation of ascorbic acid caused by metal ions through chelating the metal ions, and forming ascorbic (copigment)-metal-anthocyanin complexes [40]. Anthocyanins can also scavenge superoxide anion [31]. Duan et al. [15] reported that anthocyanins from LFP tissues strongly inhibited linoleic acid oxidation and exhibited a dose-dependent free-radical scavenging activity against DPPH radicals, superoxide anion and hydroxyl radicals (Table 3).

Table 3. Free radical scavenging activities (\%) of anthocyanins extracted from pericarp tissues of litchi fruit at harvest [9].

\begin{tabular}{|c|c|c|c|}
\hline $\begin{array}{c}\text { Amount of } \\
\text { anthocyanins } \\
(\boldsymbol{\mu g})\end{array}$ & $\begin{array}{c}\text { DPPH scavenging } \\
\text { activity } \\
\mathbf{( \% )}\end{array}$ & $\begin{array}{c}\text { Hydroxyl radical } \\
\text { scavenging activity } \\
\mathbf{( \% )}\end{array}$ & $\begin{array}{c}\text { Superoxide anion } \\
\text { scavenging activity } \\
\mathbf{( \% )}\end{array}$ \\
\hline 20 & 91 & 89 & 83 \\
100 & 93 & 93 & 89 \\
\hline
\end{tabular}

Furthermore, the degradation of deoxyribose by hydroxyl radicals was shown to be inhibited by litchi anthocyanins acting mainly as chelators of iron ions rather than by directly scavenging hydroxyl radicals. Anthocyanins from LFP tissues are also found to have excellent reducing power. The measured reducing powers of litchi anthocyanins, ascorbic acid and butylated hydroxytoluene at 100 $\mu \mathrm{g} / \mathrm{mL}$ are $3.70,0.427$ and 0.148 , respectively, indicating that LFP tissues have a strong electron- 
donating capacity [9]. In addition, the ethyl acetate fraction, procyanidin B4, procyanidin B2 and epicatechin from LFP tissues exhibit good antioxidant capability [16]. Furthermore, procyanidin B2 has greater scavenging activities against hydroxyl radicals and superoxide anion than procyanidin B4 and epicatechin, while epicatechin had the highest DPPH scavenging activity. Thus, it was suggested that litchi flavanols could be beneficial in scavenging free radical and reducing lipid peroxidation.

\section{8b. Potential anticancer activity}

Plant pigments such as flavonoids possess known pharmacological properties and are used by humans for therapeutic purposes [42-46]. Following the recognition that pigment extracts are more effective than $\mathrm{O}$-( $\beta$-hydroxyethyl)rutin in decreasing capillary permeability and fragility and for their anti-inflammatory and anti-oedema activities [34, 39, 43], it is possible that anthocyanins may replace rutin and its derivatives in the treatment of illnesses involving tissue inflammation or capillary fragility.

Wang et al. [47] reported that LFP extract exhibited potential in vitro and in vivo anticancer activity against hepatocellular carcinoma. Furthermore, the LFP extract demonstrated a dose- and time-dependent inhibitory effect on cancer cell growth [48]. Wang et al. [49] determined that the anticancer activity of LFP extract on both positive and negative breast cancers could be attributed, in part, to its DNA damaging effect, proliferating inhibition and apoptosis induction of cancer cells through up-regulation and down-regulation of multiple genes involved in cell cycle regulation and cell proliferation, apoptosis, signal transduction and transcriptional regulation, motility and invasiveness of cancer cells. It is noticed that the aglycones of the most abundant anthocyanins in LFP tissues possess the ability to inhibit the growth of human tumor cells in vitro in the micromolar range, but cyanidin-3$\beta$-galactoside and malvidin-3- $\beta$-glucoside did not directly affect tumor cell growth $[46,50]$. Thus, the identitiy of individual anthocyanins responsible the anticancer activity against hepatocellular carcinoma need to be investigated further.

The anticancer activity of the flavanols found in LFP tissues is similar to that of the anthocyanins. The anti-breast cancer activities of epicatechin, procyanidin B2, procyanidin B4 and the ethyl acetate fraction from LFP were examined [48]. Procyanidin B4 and ethyl acetate fraction showed a stronger inhibitory effect on HELF than MCF-7 while epicatechin and procyanidin B2 had lower cytotoxicities towards MCF-7 and HELF than paclitaxel. It was suggested that epicatechin and procyanidin B2 can be employed as components of anti-breast cancer drugs.

\section{8c. Interaction with DNA}

The anticancer activity of LFP water-soluble crude ethanolic extract (CEE) might result, at least in part, from inhibition of DNA synthesis, proliferation, as well as apoptosis induction of cancer cells [49]. Inhibition of DNA synthesis and proliferation of cancer cells were verified by its ability to reduce BrdU incorporation into cancer cells that correlates with decreased cell proliferation [50, 51]. Apoptosis induction was additionally determined by increased caspase-3 protein expression in tumors of the animals [13]. Non-toxic dose of LFP water-soluble CEE affected the gene expression profile of cancer cells by up-regulation of 41 genes (1.22\%) and down-regulation of 129 genes (3.84\%), involved 
in various biological functions including cell cycle regulation and cell proliferation, apoptosis, signal transduction and transcriptional regulation, and extracellular matrix/adhesion molecules, whereas the range of fold regulation varied widely with ADPRTL1 exhibiting the maximum up-regulation (29.25fold) and RHAMM exhibiting the maximum down-regulation (-15.48-fold) [49]. Furthermore, the expressions of ADPRTL1 and CYP1A1 in LFP water-soluble CEE-treated breast cancer cells increased and the expression of BIRC3 decreased significantly, suggesting that that LFP water-soluble CEE inhibited proliferation and induced apoptosis of breast cancer cells mainly through up-regulation expressions of CYP1A1 and ADPRTL1, and down-regulation of BIRC genes. Based on the recent results, LFP extract could have the ability to stabilize DNA triple-helical complexes. Figure 5 shows a proposed mechanism for cyanidin-DNA interation which leads to the formation of cyaniding-DNA copigmentation complex [6,51]. Considering that LFP extract exhibits potential anticancer activity, the elucidation of the active components present in the LFP tissues to interact DNA of cancer cells requires to be further investigated.

Figure 5. Proposed mechanism for cyanidin-DNA interation which leads to the formation of cyanidin-DNA copigmentation complex [6,51].
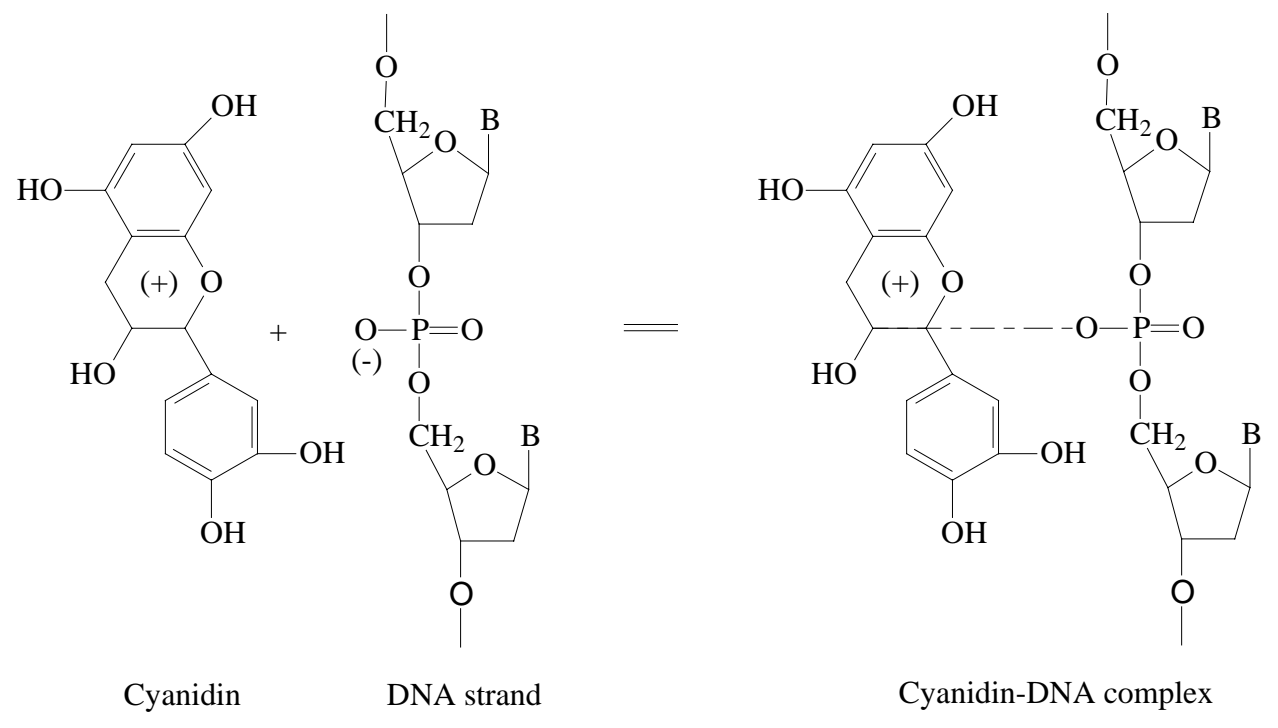

\section{Prospects}

The prospect of increasing production of litchi fruit raises expectations for increased processing opportunities for this crop. As LFP tissues account for approximately $15 \%$ of the total weight of fresh fruit, more attention to unitization of the constituents from the LFP tissues has been paid by the litchi industry in producing functional foods for consumers in relation to their beneficial effects against gastralgia, tumors and gland enlargement.

Anthocyanins and flavanols are common in LFP tissues. In recent years, many papers have been published on the in vitro antioxidant ability and anticancer activity of flavanols and anthocyanins and their other functions, as well as studies assessing the correlation between their antioxidant and anticancer capacities and chemical structure, but the in vitro antioxidant and anticancer efficacy of flavanols and anthocyanins present in LFP tissues have been less thoroughly documented, possibly due 
to the limited knowledge of their pharmacokinetics. Based on the recent study and high amount of flavonoids in LFP tissues, the constituents from LFP extract might be considered as a powerful novel antitumour agent. The anticancer activity of LFP extract could be attributed, in part to its proliferating inhibition and apoptosis induction of cancer cells through up-regulation (CYP1A1, ADPRTL1) and down-regulation (BIRC3, ADAM9, HMMR) of multiple genes, which are involved in the cell cycle regulation and cell proliferation, apoptosis, signal transduction and transcriptional regulation, motility, and invasiveness of cancer cells. ADPRTL1, CYP1A1, and HMMR might be the main molecular targets at which LFP water-soluble CEE acted.

The molecular genetics approach should provide considerable cultivar variability in terms of flavonoid contents. Selective breeding of new litchi cultivars is a significantly under-resourced area. The potential of genetic manipulation to provide an important source of flavonoids present in LFP as the compositions of anti-breast cancer drugs should be explored. Meanwhile, the litchi industry should continue to develop new approach for a better utilization of LFP tissues to increase economical benefit.

\section{Acknowledgements}

Financial support by the National Natural Science Foundation of China (Grant Nos. 30425040, 30400026 and U0631004), Guangdong Provincial Natural Science Foundation (No. 06200670) and the International Foundation for Science (Grant No. E2265/3F) is highly appreciated.

\section{References}

1. Ghosh, S.P. World trade in litchi: past, present and future. Acta Hort. 2001, 558, 23-30.

2. Jiang, Y.M.; Wang, Y.; Song, L.L.; Liu, H.; Lichter, A.; Kerdchoechuen, O.; Joyce, D.C.; Shi, J. Production and postharvest characteristics and technology of litchi fruit: an overview. Aust. J. Exp. Agric. 2006, 46, 1541-1556.

3. Peterson, J.; Dwyer, J. Flavonoids: dietary occurrence and biochemical activity. Nutr. Res. 1998, 18, 1995-2018.

4. Yao, L.H.; Jiang, Y.M.; Shi, J.; Tomás-Barberán, F.A.; Datta, N.; Singanusong, R.; Chen, S.S. Flavonoids in food and their health benefits. Plant Foods Human Nutr. 2004, 59, 113-122.

5. Clifford, A.H.; Cuppett, S.L. Review: anthocyanins - nature, occurrence and dietary burden. $J$. Sci. Food Agric. 2000, 80, 1063-1072.

6. Kong, J.M.; Chia, L.S.; Goh, N.K.; Chia, T.F.; Brouillard, R. Analysis and biological activities of anthocyanins. Phytochemistry 2003, 64, 923-933.

7. Harborne, J.B. The Flavonoids: Advances in Research since 1980; Chapman and Hall: London, 1988.

8. Tripoli, E.; Guardia, M.; Giammanco, S.; Majo, D.D.; Giammanco, M. Citrus flavonoids: Molecular structure, biological activity and nutritional properties: A review. Food Chem. 2007 (in press).

9. Cook, N.C.; Samman, S. Review: flavonoids - chemistry, metabolism, cardioprotective effects, and dietary sources. J. Nutr. Biochem. 1996, 7, 66-76. 
10. Ferguson, P.J.; Kurowska, E.; Freeman, D.J.; Chambers, A.F.; Koropatnick, D.J. A flavonoid fraction from cranberry extract inhibits proliferation of human tumor cell lines. J. Nutr. 2004, 134, 1529-1535.

11. Havsteen, B. Flavonoids, a class of natural products of high pharmacological potency. Biochem. Pharm. 1983, 32, 1141-1148.

12. Lyons-Wall, P.M.; Samman, S. Flavonoids - dietary perspectives and health benefits. Nutr. Soc. Aust. 1997, 21, 106-114.

13. Ma, T.E.; Celestino, S.; Julián, C.R. Anthocyanins in cereals. J. Chromatogr. A 2004, 1054, 129141.

14. Moon, Y.J.; Wang, X.D.; Morris, M.E. Dietary flavonoids: Effects on xenobiotic and carcinogen metabolism. Toxicol. Vitro 2006, 20, 187-210.

15. Duan, X.W.; Jiang, Y.M.; Su, X.G.; Zhang, Z.Q.; Shi, J. Antioxidant property of anthocyanins extracted from litchi (Litchi chinenesis Sonn.) fruit pericarp tissues in relation to their role in the pericarp browning. Food Chem. 2007, 101, 1382-1388.

16. Zhao, M.; Yang, B.; Wang, J.S.; Li, B.Z.; Jiang, Y.M. Identification of the major flavonoids from pericarp tissues of lychee fruit in relation to their antioxidant activities. Food Chem. 2006, 98, 737-742.

17. Zhang, D.L.; Grigor J.M.; Quantick, P.C. Changes in phenolic compounds in litchi (Litchi chinensis Sonn.) fruit during postharvest storage. Postharv. Biol. Technol. 2000, 19, 165-172.

18. Revilla, E.; Ryan, J.M.; Martín-Ortega, G. Comparison of several procedures used for the extraction of anthocyanins from red grapes. J. Agr. Food Chem. 1998, 46, 4592-4597.

19. Zhang, Z.Q.; Pang, X.Q.; Ji, Z.L.; Jiang, Y.M. Role of anthocyanin degradation in litchi pericarp browning. Food Chem. 2001, 75, 217-221.

20. Zhang, Z.Q.; Pang, X.Q.; Yang, C.; Ji, Z.L.; Jiang, Y.M. Purification and structural analysis of anthocyanins from litchi pericarp. Food Chem. 2004, 84, 601-604.

21. Prasad, U.S.; Jha, O.P. Changes in pigmentation patterns during litchi ripening: flavonoid production. Plant Biochem. J. 1978, 5, 44-49.

22. Lee, H.S.; Wicker, L. Anthocyanin pigments in the skin of lychee fruit. J. Food Sci. 1991, 56, 466-468. 23.

23. Lee, H.S.; Wicker, L. Quantitative changes in anthocyanin pigments of lychee fruit during refrigerated storage. Food Chem. 1991, 40, 263-270.

24. Sarni-Manchado, L.; Roux, E.; Guerneve, L.; Lozano, Y.; Cheynier, V. Phenolic composition of litchi fruit pericarp. J. Agr. Food Chem. 2000, 48, 5995-6002.

25. Glässgen, W.E.; Wray, S.D.; Metzger, J.W.; Seitz, H.U. Anthocyanins from cell suspension cultures of Daucus carota. Phytochemistry 1992, 31, 1593-1601.

26. Careri, M.; Mangia, A.; Musci, M. Overview of the applications of liquid chromatography mass spectrometry interfacing systems in food analysis: naturally occurring substances in food. $J$. Chromatogr. A 1998, 794, 263-297.

27. Ryan, D.; Robards, K.; Prenzler, P.; Antolovich, M. Applications of mass spectrometry to plant phenols. TAC-Trends Anal. Chem. 1999, 18, 362-372. 
28. Mouly, P.; Gaydou, E.M.; Auffray, A. Simultaneous separation of flavanone glycosides and polymethoxylated flavones in citrus juices using liquid chromatography. J. Chromatogr. A 1998, 800, 171-179.

29. Jiang, Y.M. Role of anthocyanins, polyphenol oxidase and phenols in lychee pericarp browning. $J$. Sci. Food Agric. 2000, 80, 305-310.

30. Jiang, Y.M.; Duan, X.W.; Joyce, D.C.; Zhang, Z.Q.; Li, J.R. Advances in understanding enzymatic browning of harvested litchi fruit. Food Chem. 2004, 88, 443-446.

31. Harborne, J.B.; Williams, C.A. Anthocyanins and other flavonoids. Nat. Prod. Rept. 2001, 18, 310-333.

32. Tomás-Barberán, F.A.; Clifford, M.N. Review: flavanones, chalcones and dihydrochalcones nature, occurrence and dietary burden. J. Sci. Food Agr. 2000, 80, 1073-1080.

33. Chu, Y.H.; Chang, C.L.; Hsu, H.F. Flavonoid content of several vegetables and their antioxidant activity. J. Sci. Food Agric. 2000, 80, 561-566.

34. Cooke, D.; Steward, W.P.; Gescher, A.J.; Marczylo, T. Anthocyans from fruits and vegetables Does bright colour signal cancer chemopreventive activity? Eur. J. Cancer 2005, 41, 1931-1940.

35. Espin, J.C.; Soler-Rivas, C.; Wichers, H.J.; Garcia-Viguera, C. Anthocyanin-based natural colorants: a new source of antiradical activity for foodstuff. J. Agr. Food Chem. 2000, 48, 15881592.

36. Hertog, M.G.L.; Hollman, P.C.H.; Katan, M.B. Content of potentially anticarcinogenic flavonoids of 28 vegetables and 9 fruits commonly consumed in the Netherlands. J. Agr. Food Chem. 1992, 40, 2379-2383.

37. Duthie, G.G.; Duthie, S.J.; Kyle, J.A.M. Plant polyphenols in cancer and heart disease: implications as nutritional antioxidants. Nutr. Res. Rev. 2000, 13, 79-106.

38. Mann, J. Natural products in cancer chemotherapy: past, present and future. Nat. Rev. Cancer 2002, 2, 143-148.

39. Nijveldt, R.J.; Van Nood, E.; Van Hoorn, D.E.C.; Boelens, P.G.; Van Norren, K.; Van Leeuwen, P.A.M. Flavonoids: a review of probable mechanisms of action and potential applications. Amer. J. Clin. Nut. 2001, 74, 418-425.

40. Suolinna, E.M.; Buchsbaum, R.N.; Racker, E. The effect of flavonoids on aerobic glycolysis and growth of tumor cells. Cancer Res. 1975, 35, 1865-1872.

41. Lottto, S.B.; Frei, B. Consumption of flavonoid-rich foods and increased plasma antioxidant capacity in humans: Cause, consequence, or epiphenomenon? Free Rad. Biol. Med. 2006, 41, 1727-1746.

42. Cai, Y.; Luo, Q.; Sun, M.; Corke, H. Antioxidant activity and phenolic compounds of 112 traditional Chinese medicinal plants associated with anticancer. Life Sci. 2004, 74, 2157-2184.

43. Middleton, E.; Kandaswami, C. Effects of flavonoids on immune and inflammatory cell functions. Biochem. Pharmacol. 1992, 43, 1167-1179.

44. Yochum, L.A.; Kushi, L.H.; Meyer, K.; Folsom, A.R. Dietary flavonoid intake and risk of cardiovascular disease in postmenopausal women. Amer. J. Epidemiol. 2000, 149, 943-949.

45. Hirano, T.; Gotoh, M.; Oka, K. Natural flavonoids and lignans are potent cytostatic agents against human leukemia HL-60 cells. Life Sci. 1994, 55, 1061-1069. 
46. Mukherjee A.K.; Basu S.; Sarkar N.; Ghosh A.C. Advances in cancer therapy with plant based natural products. Curr. Med. Chem. 2001, 8, 1467-1486.

47. Wang X.; Wei Y.; Yuan S.; Liu G.; Lu Y.; Zhang J.; Wang W. Potential anticancer activity of litchi fruit pericarp extract against hepatocellular carcinoma in vitro and in vivo. Cancer Lett. 2006, 239, 144-150.

48. Zhao M.; Yang B.; Wang J.; Liu Y.; Yu L.; Jiang Y.M. Immunomodulatory and anticancer activities of flavonoids extracted from litchi (Litchi chinensis Sonn.) pericarp. Int. Immunopharmacol. 2007, 7, 162-166.

49. Wang X.; Yuan S.; Wang J.; Lin P.; Liu G.; Lu Y.; Zhang J.; Wang W.; Wei Y. Anticancer activity of litchi fruit pericarp extract against human breast cancer in vitro and in vivo. Toxicol. Appl. Pharm. 2006, 215, 168-178.

50. Meiers S.; Kemeny M.; Weyand U.; Gastpar R.; Angerer E.; Marko D. The anthocyanidins cyanidin and delphinidin are potent inhibitors of the epidermal growth-factor receptor. J. Agric. Food Chem. 2001, 49, 958-962.

51. Mas T.; Susperregui J.; Berke B.; Cheze C.; Moreau S.; Nuhrich A.; Vercauteren J. DNA triplex stabilization property of natural anthocyanins. Phytochemistry 2000, 53, 679-687.

Sample availability: Not applicable.

(c) 2007 by MDPI (http://www.mdpi.org). Reproduction is permitted for noncommercial purposes. 